\title{
Congenital anomalies in Primorsky region
}

\author{
P. Kiku ${ }^{\mathrm{a}, *}, \mathrm{~S}$. Voronin $^{\mathrm{c}}$ and K. Golokhvast ${ }^{\mathrm{b}}$ \\ ${ }^{a}$ Far Eastern Federal University, School of Biomedicine, Vladivostok, Russia \\ ${ }^{\mathrm{b}}$ Far Eastern Federal University, School of Natural Sciences, Vladivostok, Russia \\ 'State Autonomous Health Institution Regional Clinical Center, Vladivostok, Russia
}

*Corresponding author. E-mail: 1me@list.ru

\begin{abstract}
BACKGROUND: According to WHO hereditary diseases and congenital malformations contribute significantly to the health of population. Thus, the problems of epidemiology, clinical presentation, diagnosis and treatment of congenital abnormalities are of interest for many researchers [2]. In addition, the dynamic accounting for the incidence of congenital malformations and hereditary diseases allows the researchers to assess the ecological situation in the region [1]. The occurrence of congenital anomalies in the world varies; it depends heavily on how carefully the data is collected [4]. Multifactorial or polygenic diseases develop under the influence of environmental factors in the presence of defective genes. They can constitute up to $90 \%$ of all chronic pathology [2-5].
\end{abstract}

OBJECTIVE: To determine the incidence of congenital anomalies under the influence of environmental factors.

METHODS: The study used the methodology of system evaluation of congenital anomalies incidence in Primorsky region, depending on bio-climatic and environmental conditions. The authors used health statistics for the period from 2000 to 2014, F.12 class for congenital abnormalities in adolescents and children that were compared in geographical and temporal aspects with environmental factors of 33 settlements in Primorsky region. The environment is represented by nature and climate ( 6 factor modules) and sanitation ( 7 factor modules) blocks of factors. When formalizing the information database of the environment a specially developed 10-point assessment scale was used. Statistical processing of the information was carried out using Pearson's chi-squared test and multiple regression method from SSPS application program package.

RESULTS: The study found that over the 15-year period the level of congenital abnormalities in children increased by $27.5 \%$ and in adolescents - by $35.1 \%$, and in 2014 it amounted to 1687.6 and 839.3 per 100000 people, respectively. The predictive model shows a steady further growth of this pathology. The incidence has increased dramatically since 2000 . This was due to the beginning of activities of medicogenetic service since 1998: the legal framework and information database were created, the flow of pregnant women was formed actively, and invasive prenatal diagnosis was introduced.

Incidence of congenital anomalies has a reliable statistical association (chi-square) with bioclimatic zones and ecological situation. The high level of pathology is observed in both teenagers and children in the critical environmental situation areas, where there are enterprises of coal, mining and chemical industry, ship repair, construction, engineering sites, and areas with intensive chemical use and improvement of agriculture. For the most part these are cities and districts of the region where more than a half of the major manufacturing plants of the 1st and 2nd hazard classes are located. Exceeding the maximum allowable concentrations (MAC) of harmful substances in the air, soil, and water in these areas 
often reaches tenfold. It should be noted that in the territories with the critical environmental situation a relatively high level of malformations is observed in adolescents in the continental bioclimatic zone, and in children - on the coast, suggesting the influence of different climatic factors. Also a high level of the same congenital anomalies was revealed in children in bioclimatic zones of the coast and transition zones with the intense environmental situation.

According to the results of the regression analysis, the varying degrees of influence of ecological and hygienic factors on the incidence of congenital anomalies were determined. In children, up to $77.3 \%$ of the spread of pathology depends on the complex of parameters of the environment; the proportion of the influence of sanitary and hygienic indicators is $63.1 \%$, and natural and climatic indicators $-14.2 \%$. Such factors as the characteristics of the soil condition, the level of air pollution, chemical pollution and adverse physical factors in urban and rural settlements, transport load, the presence of hazard-class companies, and observance of sanitary protection zones are of the most significance. The influence of a complex of ecological and hygienic factors on the incidence of pathology in adolescents was $60.0 \%$. The contribution of sanitary and hygienic parameters was $44.5 \%$, and natural and climatic ones $-15.5 \%$. Chemical pollution and adverse physical factors in urban and rural areas, the level of air pollution, traffic loads, and condition of the soil influence the most. Assessing the results of the analysis one should note that the incidence of congenital abnormalities in both children and adolescents depends largely on the same modular sanitary factors, but with varying degrees of influence. At the same time the natural and climatic block of factors has almost the same degree of influence in these age groups.

CONCLUSIONS: A significant increase of congenital anomalies in children and adolescents is registered in Primorsky Region, and the same is projected for the next 5 years.

- The incidence of congenital anomalies in the region depends on bioclimatic zones and ecological situation. The highest level of pathology is observed in children in the coastal bioclimatic zone, and in adolescents, in the continental bioclimatic zone in areas with critical environmental situation.

- Varied degree of influence on the level of congenital anomalies by a complex of sanitary and climatic factors is determined. The leading role (44.5-63.1\%) belongs to sanitary and hygienic parameters of the life environment.

- The results obtained make it possible to develop a set of organizational, diagnostic and treatment, and preventive measures for the correction of health of the population.

Keywords: Congenital, malformations, anomalies, hereditary diseases, population, children, adolescents

\section{References}

[1] Baranov VS. Ecological genetics. 2003. No.1. pp 22-29. Russian

[2] Hereditary diseases control: Trans. from English. Report of WHO Scientific Group. WHO Technical Report Series. - M.: Medicine, 2007. No. 865. 134 p. Russian

[3] Bochkov N.P. Clinical genetics. M.: GEOTAR-MED. 2004. 480 p. Russian

[4] Forfar JO. Campbell AGM, McIntosh N, eds. Forfar and Arniel's textbook of pediatrics,4th/Ed. Edinburgh, Churchill livingstone. 2010. pp. 24-27.

[5] Rimoins DL, Connor MJ, Pyeritz RE. Emery and Rimoin's Principles and Practice of Medical Genetics. London, N.-Y., Toronto: Churchill Livingstone. 2012. 122 p. 